\title{
Deficient melanocortin-4 receptor causes abnormal reproductive neuroendocrine profile in female mice
}

\author{
Xiaolin Chen ${ }^{1,2}$, Lili Huang ${ }^{1}$, Hwee Y Tan ${ }^{1}$, Hongzhuo Li ${ }^{1}$, Ying Wan ${ }^{1}$, Michael Cowley ${ }^{3}$, \\ Johannes D Veldhuis ${ }^{4}$ and Chen Chen ${ }^{1}$ \\ ${ }^{1}$ School of Biomedical Science, University of Queensland, St Lucia, Brisbane, Queensland, Australia, \\ ${ }^{2}$ Endocrinology Department, Renmin Hospital of Wuhan University, Wuchang District, Wuhan, Hubei Province, \\ People's Republic of China, ${ }^{3}$ Department of Physiology, Monash University, Clayton, Victoria, Australia and \\ ${ }^{4}$ Endocrine Research Unit, Mayo School of Graduate Medical Education, Clinical Translational Science Center, \\ Mayo Clinic, Rochester, Minnesota, USA
}

Correspondence should be addressed to C Chen; Email: chen.chen@uq.edu.au

\begin{abstract}
Deletion of the melanocortin-4-receptor (Mc4r) gene in mice causes hyperphagia, followed by hyperinsulinemia, obesity and progressive infertility. Evidence shows that the number of developed corpora lutea is reduced in obese MC4R-knockout (MC4R KO) female mice, but the mechanism is unclear. The effect of hyperphagia and obesity by MC4R KO on pulsatile luteinizing hormone (LH) secretion and ovulation remains unknown. In MC4R KO mice and wild-type littermates (WT LM) during the diestrus period throughout different ages, we examined and monitored their metabolic status, pulsatile LH profiles, follicular morphology and the number of corpora lutea. MC4R KO mice were hyperphagic, obese, hyperglycemic, hyperinsulinemic and demonstrated insulin resistance and hepatic steatosis. Irregular estrous cycles and significant changes in the LH secretion profiles were observed in sexually matured 16- to 28-week MC4R KO mice, without any difference in testosterone levels. In addition, MC4R KO mice at 16 weeks of age had significantly fewer corpora lutea than same age WT LM mice. The ovary examinations of MC4R KO mice at 28 weeks of age showed predominantly antral and preovulatory follicles with no corpora lutea. These findings were consistent with the decrease in total, pulsatile, mass and basal LH releases in MC4R KO mice. The characteristics of hormone profiles in obese MC4R KO mice indicate that $\mathrm{MC4R}$ plays an important role in regulating LH release, ovulation and reproductive ability probably via hyperphagiainduced obesity. Further study of correlation between metabolic and reproductive regulatory hormones is warranted to dissect the pathological mechanism underlying obesity-induced infertility.

Free Chinese abstract: A Chinese translation of this abstract is freely available at http://www.reproduction-online.org/content/153/3/267/ suppl/DC1.

Reproduction (2017) $153267-276$
\end{abstract}

\section{Introduction}

The hypothalamic-melanocortin system plays an important role in the regulation of energy homeostasis and feeding behavior via the melanocortin receptors (Morton et al. 2006, Tung et al. 2006). The prevention of overeating and obesity occurs predominantly through the activation of melanocortin-4 receptor (MC4R) (Huszar et al. 1997, Weide et al. 2003, Xu et al. 2013). Obesity due to excess nutrition has also been linked to reproductive dysfunction (Leisegang et al. 2014, Wu et al. 2014, Crujeiras \& Casanueva 2015). Obese MC4R knockout (MC4R KO) male mice are characterized by erectile dysfunction and changed sexual behavior (Van der Ploeg et al. 2001). Obese MC4R KO female mice demonstrated a reduction in the number of developed corpora lutea and decreased litter sizes (Sandrock et al. 2009).
The physiological mechanism of how obesity contributes to infertility is still unclear. Reproductive function is controlled by the hypothalamic-pituitarygonadal axis, which is regulated by numerous endogenous and environmental factors (Brothers et al. 2010). Various studies have shown that insulin signaling has been implicated in the regulation of reproductive function by acting on peripheral gonadal tissue and parts of the central nervous system associated with the impact of obesity on reproductive health (Wu et al. 2012, 2014, Sanchez-Garrido \& Tena-Sempere 2013). Insulin has been demonstrated to be an important regulator of the hypothalamic-pituitary-gonadal axis (Sliwowska et al. 2014). Gonadotropin-releasing hormone $(\mathrm{GnRH})$ is the key hormone within the hypothalamic-pituitarygonadal axis that regulates reproduction and sexual behavior. The pulsatile secretion of $\mathrm{GnRH}$ from the 
hypothalamus stimulates the anterior pituitary to synthesize and secrete luteinizing hormone (LH) and follicle-stimulating hormone (FSH) (Foster et al. 2006). $\mathrm{LH}$ and $\mathrm{FSH}$ act on the ovaries to promote the maturation of follicular cells, with pulsatile LH secretion closely mimicking the pulsatile pattern of $\mathrm{GnRH}$ release from the hypothalamus (Clarke \& Cummins 1985). The surge in $\mathrm{LH}$ secretion triggers ovulation by inducing the rupture of the preovulatory follicles and the release of the ovum. $\mathrm{LH}$ and $\mathrm{FSH}$ also stimulate ovarian maturation and corpus luteum formation in female mice (Levi-Setti et al. 2004, Palermo 2007). The absence or deregulation of LH pulsatile pattern and surge results in no ovulatory cycle. It is therefore necessary to investigate the pattern of $\mathrm{LH}$ secretion in sexually mature mice with and without overeating and obesity.

Current studies in MC4KO mice provide morphological evidence of ovary dysfunction without detailed analysis of pulsatile $\mathrm{LH}$ profiles. MC4R KO mice provide a suitable model to investigate the effect of over-nutrition (via overeating behavior not high-fat food leading to obesity, similar to human situation) on the pulsatile pattern of $\mathrm{LH}$ secretion. As the MC4R KO female mice show obese and infecund characteristics similar to those seen in polycystic ovary syndrome (PCOS) patients (Lerchbaum et al. 2014), the levels of testosterone and FSH have also been investigated in this study. This work provides first evidence on $\mathrm{LH}$ secretion profiles and ovarian histological changes in hyperphagia of normal food-induced obesity in MC4R KO female mice.

\section{Materials and methods}

\section{Animals and general conditions}

Wild-type C57/BL6 female mice were obtained from the University of Queensland Biological Resources, Australian Institute for Bioengineering and Nanotechnology (UQBR,

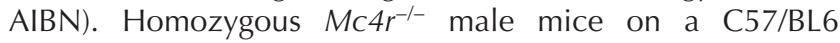
background were provided by Professor Michael Cowley (Monash University, Melbourne, Australia) and bred with

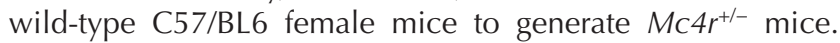

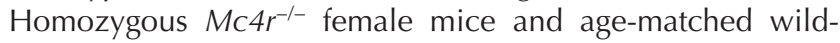
type littermates were obtained from heterozygote $\mathrm{Mc}_{\mathrm{Cr}} \mathrm{r}^{+-}$ mice. Mice were pair-housed in a 12-h light/darkness cycle (lights at 06:30 h and off at 18:30h). Room temperature (RT) was maintained at $22 \pm 2{ }^{\circ} \mathrm{C}$. Animals had free access to water and standard chow for the duration of all experiments. All experimental procedures were performed with the approval of the University of Queensland Animal Ethics Committee.

\section{Genotyping and phenotypic characteristics of MC4R KO mice}

To verify the deletion of the Mc4r gene in homozygous mutants, the toe tip ( $1 \mathrm{~mm}$ ) was collected and genomic DNA was isolated by REDExtrac-N-Amp Tissue PCR kit (XNATR, Sigma). Primers used for genotyping are as previously published (Shaw et al. 2005):
Mc4r primer sequences (forward) 5'-GGA AGA TGA ACT CCA CCC ACC-3', (reversed) 5'-GAC GAT GGT TTC CGA CCC ATT-3' and PGKR3: 5'-TTC CCA GCC TCT GAG CCC AGA-3'. Homozygous Mc4r KO mice were identified by the presence of $405 \mathrm{bp}$ for Mc4r KO allele and $313 \mathrm{bp}$ for the WT LM allele.

To monitor the development of hyperphagia, food consumption was measured daily from 6 to 17 weeks of age. Body weight was recorded from 6 to 28 weeks of age. Body length and adiposity was measured by the time of killing at 16 and 28 weeks of age. At the time of killing (between 09:00 $\mathrm{h}$ and 10:00 h), mice were anesthetized with a single i.p. injection of sodium pentobarbitone $(32.5 \mathrm{mg} / \mathrm{mL}, 1 \mathrm{PO} 643-1$; Virbac Animal Health, Milperra, NSW, AUS). Body length was measured from nose to anus. The right subcutaneous and visceral fat including subperitoneal, inguinal, gonadal and perirenal were dissected out, and the fat mass was determined.

\section{Characterization of metabolic profiles in MC4R KO mice}

Glucose tolerance tests (GTT) were performed at 20 weeks of age. Briefly, mice were injected with a single dose of glucose (i.p., $2 \mathrm{~g} / \mathrm{kg}$ body weight) after $12 \mathrm{~h}$ of fasting. A tail-tip blood sample was collected immediately prior to the injection and at 30,60, 90 and 120-min intervals after the injection. Blood glucose was determined using the Start-Strip Xpress glucometer (Waltham, MA, USA). Insulin tolerance tests (ITT) were performed at 20 weeks of age. Starting at 08:00 h, mice were fasted for $6 \mathrm{~h}$ with free access to water. At 14:00 h, mice were injected intraperitoneally with insulin $(0.5 \mathrm{U} / \mathrm{kg}$; Sigma). Tail-tip blood samples were collected immediately before the injection and at 15, 30 and $45 \mathrm{~min}$ after the injection (Bowe et al. 2014). Blood glucose concentration was determined as described in GTT. At 16 and 28 weeks of age, mice were killed and terminal blood samples were collected into ethylenediamine tetra-acetate (EDTA) tubes (1.6 mg/mL blood) (D51588; Sarstedt Australia Pty Ltd, SA, AUS). Plasma was collected for future hormonal analysis of insulin, testosterone and follicle-stimulating hormone ( $\mathrm{FSH}$ ) via commercial kits (Ultra Sensitive Mouse Insulin ELISA kit Crystal Chem Inc., Downers Grove USA. FSH and testosterone ELISA kit MyBioSource, Inc., San Diego USA). The coefficients of variation were $<10 \%$. All blood samples for testing FSH and testosterone were collected at diestrus.

\section{Assessment of estrous cycles and pulsatile $L H$ release in MC4R KO mice}

MC4R KO female mice showed a reduced reproductive ability along age increase. To investigate the change in reproductive endocrinology, experiments were started from matured age of 8 weeks to the time with significant compromised reproductive function at 26-28 weeks. A vaginal cytology method was used to determine the stage of the oestrous cycle from 8 to 28 weeks of age mice. The stages of the oestrous cycle were assessed based on vaginal cytology as follows: predominant nucleated epithelial cells indicated the proestrus stage, predominant cornified epithelial cells indicated the estrus stage, predominant multinucleated leukocytes and a few cornified epithelia cells indicated the metestrus stage and predominant leukocytes 
indicated the diestrus stage (Byers et al. 2012). Daily vaginal smears were taken between 09:00 h and 11:00 h.

The estrous cycle is a continuum of approximately $4-5$ days in mice. The proestrus is at $12-24 \mathrm{~h}$, whereas the estrus may last 1-2 days, and diestrus of 2-3 days. On the day of estrus, the level of the $\mathrm{LH}$ concentration is very low in mouse (Y Wan, F Steyn, L Huang, JD Veldhuis, C Chen, unpublished observations). During the diestrus, pulsatile LH profile shows high frequency and low amplitude with high basal levels. To identify difference of LH profiles between MC4R KO and WT mice, blood samples of 10-min interval were collected during diestrus from different age mice and processed as previously described (Steyn et al. 2013). Starting at 08:00 h, 36 sequential $2 \mu \mathrm{L}$ tail-tip blood samples were collected from each mouse in diestrus at 10-min intervals. Blood samples were transferred immediately to $58 \mu \mathrm{L}$ of $0.05 \%$ PBS-T, mixed and placed on dry ice. The samples were stored at $-80^{\circ} \mathrm{C}$ before analysis and were processed by an in-house sensitive sandwich ELISA to determine whole blood $\mathrm{LH}$ content. The minimum detectable dose of mouse $\mathrm{LH}$ is $0.0039 \mathrm{ng} / \mathrm{mL}$. The intra-assay coefficient of variation was $7.50 \%$. The inter-assay coefficient of variation was $3.36 \%$ (Steyn et al. 2013).

\section{Ovary histology}

Ovaries were collected from mice at the diestrus stage at the time of killing. Left and right ovaries were fixed in $4 \%$ paraformaldehyde for $24 \mathrm{~h}$ at $4{ }^{\circ} \mathrm{C}$, and then transferred to $30 \%$ sucrose and embedded in optimal cutting temperature compound (OCT). Ovaries were serially sectioned at $7 \mu \mathrm{m}$ thickness along the longitudinal plane. Total 96 sections were collected and stained with hematoxylin and eosin (H\&E). Sections were imaged with an Aperio ScanScope XT slide scanner (Aperio Technologies, Vista, CA, USA).

Follicles and corpora luteal were counted in every 4th ovary section. According to morphological criteria (Myers et al. 2004), the follicles were classified as following: primordial follicles, secondary follicles, preantral follicles, antral follicles and preovulatory follicles. In our study, histological examination showed a morphologically undifferentiated appearance of primordial follicles and primary follicles. Consequently, follicles with one layer of cells surrounding the oocytes were counted as primary follicles. To avoid double counting, only follicles with an apparent nucleus of the oocyte were counted. Established and functional corpora luteal were counted in every 4th ovary section. Regressing and involuting corpora luteal were not counted.

\section{Liver histology}

A selected piece of fresh liver tissue was immediately collected and directly embedded on the mould of the cryostat by pouring OCT around the tissue. The tissue was kept frozen on dry ice and then stored at $-80^{\circ} \mathrm{C}$. The tissue was then sectioned to $12 \mu \mathrm{m}$ thickness. The liver sections were stained by Oil Red O (ORO) working solution for $10 \mathrm{~min}$ and rinsed under running tap water for $30 \mathrm{~min}$ (Mehlem et al. 2013). The liver sections were also stained with $\mathrm{H} \& \mathrm{E}$. Sections were imaged on an Aperio ScanScope XT slide scanner for comparison analysis.

\section{Reverse transcription polymerase chain reaction (RT-PCR)}

Total RNA was isolated from the pituitary gland, ovary, liver, muscle and fat tissues collected from WT LM female mice using TRIzol and RNase reagents (Invitrogen) according to the manufacturer's recommended protocol. One microgram total RNA was subjected to complementary DNA synthesis using a QuantiTect cDNA synthesis kit (QIAGEN). The total reaction volume was $24 \mu \mathrm{L}$. Mc $4 r$ primer sequences were the same as before. The sequences of primers used for amplification were 5'-GAGGCCAGATGCTGAGAATAAC-3' as a sense primer and 5'-CCTCGCTGTAGAAGAAGGAAAC-3' as an antisense primer for insulin receptor. PCR products were electrophoresed on $2 \%$ agarose gels and visualized using ethidium bromide staining and ultraviolet excitation. The relative expression of insulin receptor mRNA was measured using an Image) analysis system.

\section{Statistical analysis}

Data are presented as means \pm S.E.M. Age-related comparisons between MC4R KO mice and WT LM mice were analyzed by two-way ANOVA with Tukey's multiple comparison tests. All measures (excluding deconvolutional analysis) were obtained using GraphPad Prism (version 6.0; GraphPad Software). $P<0.05$ was considered statistically significant. The quantitative features underlying $\mathrm{LH}$ secretion and clearance associated with the observed concentration profiles were determined by deconvolutional analysis, as described previously (Steyn et al. 2013).

\section{Results}

\section{Loss of MC4R results in hyperphagia, increased body weight, length, fat pad mass, liver size and hepatic steatosis}

During the observation period of 8-16 weeks, MC4R $\mathrm{KO}$ mice were hyperphagic, showing a significant increase in food consumption compared to WT LM mice (Table 1). At 8 weeks of age, MC4R KO mice were significantly heavier in comparison to WT LM mice, and this increase in body weight continued to more than 28 weeks. By 28 weeks, the body weights of MC4R KO mice were twice those of WT LM mice (Table 1). The body length of MC4R KO mice was significantly increased $(11 \%$ more $)$ than that of WT LM mice. However, there was no significant difference of increasing rate in body length from 16 to 28 weeks between MC4R KO and WT LM mice (Table 1). Liver weight, as well as adipose fat mass in MC4R KO mice at 16- and 28-week age was significantly greater than agematched WT LM mice (Table 1).

Increased liver weight in MC4R KO mice is associated with histological abnormality. Liver tissues from 28-week MC4R KO mice exhibited a yellow texture with enriched adipose tissues. Representative histological sections of liver from WT LM and MC4R KO mice were 
Table 1 Phenotypic and metabolic profiles characteristics of MC4R KO mice.

\begin{tabular}{|c|c|c|c|c|c|c|}
\hline & WT LM & MC4R KO & WT LM & MC4R KO & WT LM & MC4R KO \\
\hline Group & 8 weeks & 8 weeks & 16 weeks & 16 weeks & 28 weeks & 28 weeks \\
\hline Food intake (g/day) & $2.86 \pm 0.13$ & $4.35 \pm 0.08^{\#}$ & $2.84 \pm 0.16$ & $4.97 \pm 0.15^{\#}$ & - & - \\
\hline Body weight (g) & $18.90 \pm 0.39$ & $24.96 \pm 1.11^{\#}$ & $22.54 \pm 0.58$ & $38.49 \pm 2.05^{*}$ & $24.07 \pm 0.72$ & $48.69 \pm 1.00^{*}$ \\
\hline Body length $(\mathrm{cm})$ & - & - & $8.10 \pm 0.09$ & $9.34 \pm 0.09$ & $8.30 \pm 0.10$ & $9.43 \pm 0.06$ \\
\hline Subcutaneous fat mass (g) & - & - & $0.13 \pm 0.01$ & $0.66 \pm 0.08^{*}$ & $0.19 \pm 0.02^{\star}$ & $1.09 \pm 0.04^{*, \#}$ \\
\hline Visceral fat mass (g) & - & - & $0.32 \pm 0.02$ & $2.09 \pm 0.24^{*}$ & $0.57 \pm 0.06^{\Delta}$ & $3.36 \pm 0.10^{*, \#}$ \\
\hline Liver mass (g) & - & - & $0.95 \pm 0.05$ & $1.85 \pm 0.15^{*}$ & $1.00 \pm 0.07$ & $2.07 \pm 0.13^{*}$ \\
\hline FBG $(\mathrm{mmol} / \mathrm{L})$ & $4.53 \pm 0.15$ & $5.32 \pm 0.70$ & $3.94 \pm 0.25$ & $5.14 \pm 0.38^{\star}$ & $3.41 \pm 0.15$ & $5.64 \pm 0.39^{\#}$ \\
\hline PBG (mmol/L) & $7.57 \pm 0.29$ & $8.22 \pm 0.62$ & $6.77 \pm 0.34$ & $8.57 \pm 0.38^{\Delta}$ & $7.24 \pm 0.34$ & $7.79 \pm 0.26$ \\
\hline Fasting insulin (ng/mL) & $0.55 \pm 0.05$ & $0.53 \pm 0.10$ & $0.42 \pm 0.14$ & $0.92 \pm 0.12^{\star}$ & - & - \\
\hline Fed insulin $(\mathrm{ng} / \mathrm{mL})$ & $1.30 \pm 0.29$ & $0.88 \pm 0.17$ & $0.68 \pm 0.05$ & $4.46 \pm 2.80^{\Delta}$ & - & - \\
\hline
\end{tabular}

Data are presented as mean \pm S.E.M. $n=6-8$ per group.

${ }^{*} P<0.0001,{ }^{\sharp} P<0.001,{ }^{\Delta} P<0.01,{ }^{\star} P<0.05$.

FBG, fasting blood glucose; PBG, postprandial blood glucose.

stained with H\&E or ORO. The histological sections of liver from MC4R KO mice exhibited hepatic steatosis (data not shown).

\section{Loss of MC4R results in hyperglycemia, hyperinsulinemia and development of glucose intolerance and insulin resistance}

To determine the metabolic profiles of MC4R KO mice, we measured the circulating levels of insulin and glucose. Fasting and postprandial blood glucose levels were higher in MC4R KO mice when compared to WT LM at as early as 8 weeks of age, with the statistical significance at 16 and 28 weeks of age. Hyperglycemia in MC4R KO mice occurs alongside an increase in circulating levels of insulin (Table 1). To further determine glucose disposal and insulin sensitivity, we performed GTT and ITT in MC4R KO and WT LM at 20 weeks of age. MC4R KO mice demonstrated impaired glucose tolerance and insulin resistance (Tables 2 and 3 ).

\section{Loss of MC4R results in altered estrous cycle and a progressive reduction in total, pulsatile and mass of $\mathrm{LH}$ secreted per burst}

To assess the function of the ongoing reproductive cycles of the mice, vaginal cytology was performed for 21 days during age ranges of 11- to 13-week, 16- to 18-week and 23- to 25-week-old mice respectively and estrous cycles were evaluated. All 11- to 13-week mice had normal 4- to 5-day estrous cycles. MC4R KO mice had the same estrous cycle pattern as WT LM mice (Fig. 1A, B and C). However, MC4R KO mice exhibited irregular estrous cycles at 16 weeks of age with longer estrous cycles than that in WT LM mice. These MC4R KO mice had less time at proestrus than that in WT LM mice (Fig. 1D, E and F). In the 23- to 25-week age groups, MC4R KO mice had no proestrus, with longer time at estrus and metestrus phases and less time at diestrous than that in WT LM mice (Fig. 1G, $\mathrm{H}$ and I).

Pulsatile LH secretion was assessed during diestrus at three age groups: 10 weeks, 18 weeks and 26 weeks. Representative LH secretion profiles (Fig. 2A, B and C, left panel) and the corresponding output figures (Fig. 2A, $\mathrm{B}$ and $\mathrm{C}$, right panel) illustrated the onset of pulsatile $\mathrm{LH}$ secretion in MC4R KO and corresponding WT LM mice at these age groups. MC4R KO and WT LM mice exhibited pulsatile release of LH by 10 and 18 weeks of age respectively. There was no significant difference in total, pulsatile rate and basal rate of $\mathrm{LH}$ secretion, and mass of LH secreted per burst between MC4R KO and WT LM mice at 10-week age as determined by deconvolutional analysis (Table 4). At 18 weeks, MC4R KO mice showed a decrease in basal LH levels and reduced irregularity compared with the WT LM mice (Table 4). At 26 weeks, MC4R KO mice showed significant reduction in total, pulsatile, per burst, basal LH secretion, the number of secretory events and significant increased regularity (Table 4). Approximate entropy (ApEn) of pulsatile hormone profile is used to quantify the regularity with 0.35 as the least irregularity. It is therefore believed that reduced reproductive ability is due to decrease in total amount and pulse frequency of $\mathrm{LH}$ release and may also be related to the increased regularity of LH pulsatile profiles.

Table 2 Glucose tolerance in 20-week MC4R KO and WT LM mice.

\begin{tabular}{lcccccc}
\hline & \multicolumn{5}{c}{ Plasma glucose $(\mathrm{mmol} / \mathrm{L})$} \\
\cline { 2 - 6 } Group & $0 \mathrm{~min}$ & $30 \mathrm{~min}$ & $60 \mathrm{~min}$ & $90 \mathrm{~min}$ & $120 \mathrm{~min}$ & AUC $_{\text {Glucose }}(\mathrm{mmol} \times \mathrm{min} / \mathrm{L})$ \\
\hline WT LM & $3.29 \pm 0.22$ & $14.00 \pm 0.71$ & $10.11 \pm 0.54$ & $7.34 \pm 0.71$ & $6.31 \pm 0.46$ & $67.84 \pm 3.35$ \\
MC4R KO & $5.71 \pm 0.37^{\Delta}$ & $20.49 \pm 1.04^{\star}$ & $14.24 \pm 1.58^{\star}$ & $10.39 \pm 1.03^{\star}$ & $9.34 \pm 1.05^{\star}$ & $92.53 \pm 7.55^{\Delta}$ \\
\hline
\end{tabular}

Data are presented as mean \pm S.E.M. $n=6-8$ per group.

${ }^{\sharp} P<0.001, \Delta P<0.01,{ }^{\star} P<0.05$.

$\mathrm{AUC}_{\mathrm{Glucose}}$ area under the curve of glucose. 
Table 3 Insulin tolerance in 20-week MC4R KO and WT LM mice.

\begin{tabular}{|c|c|c|c|c|c|}
\hline \multirow[b]{2}{*}{ Group } & \multicolumn{4}{|c|}{ Plasma glucose $(\mathrm{mmol} / \mathrm{L})$} & \multirow[b]{2}{*}{$\mathbf{A U C}_{\text {Glucose }}(\mathrm{mmol} \times \mathrm{min} / \mathrm{L}$} \\
\hline & $0 \mathrm{~min}$ & $15 \mathrm{~min}$ & $30 \mathrm{~min}$ & $45 \mathrm{~min}$ & \\
\hline $\begin{array}{l}\text { WT LM } \\
\text { MC4R KO }\end{array}$ & $\begin{array}{l}6.77 \pm 0.45 \\
8.23 \pm 0.57\end{array}$ & $\begin{array}{l}4.84 \pm 0.32 \\
6.84 \pm 0.59\end{array}$ & $\begin{array}{l}3.59 \pm 0.50 \\
5.98 \pm 0.39 \star\end{array}$ & $\begin{array}{l}2.33 \pm 0.67 \\
5.90 \pm 0.56^{\Delta}\end{array}$ & $\begin{array}{l}194.69 \pm 18.05 \\
298.15 \pm 19.26^{\star}\end{array}$ \\
\hline
\end{tabular}

Data are presented as mean \pm S.E.M. $n=6-8$ per group.

${ }^{\Delta} P<0.01,{ }^{\star} P<0.05$.

$\mathrm{AUC}_{\mathrm{Glucose}}$ area under the curve of glucose.

\section{Altered $\mathrm{LH}$ secretion patterns in MC4R KO mice is associated with changes in the number of follicles and corpora lutea in ovaries}

The number of follicles at all stages and corpora lutea in 16-week and 28-week WT LM and MC4R KO mouse ovaries were counted (Fig. 3A, B, C and D). At 16-week age, the number of follicles at all stages was not significantly different between ovaries from WT LM and MC4R KO mice. At 28-week age, the number of follicles at antral and preovulatory stages in MC4R KO ovaries was significantly increased than that in WT LM mice. However, there was no significant difference in the primary, secondary or preantral follicle numbers between WT LM and MC4R KO mice (Fig. 3E).

Corpora lutea were quantified as a marker of recent ovulation. Histological sections of ovaries revealed that 16-week-old MC4R KO mouse ovaries had fewer corpora lutea than those in WT LM mouse ovaries. In addition, corpora lutea were absent in 28-week MC4R KO mouse ovaries consistent with significantly dysfunctional fertility (Fig. 3F).

Alongside with the changes in the number of follicles and corpora lutea in ovaries, we observed a reduction in circulating FSH levels in MC4R KO mice when compared to age-matched WT LM mice (Fig. 4A). In contrast, no difference was observed in circulating testosterone levels between WT LM and MC4R KO mice (Fig. 4B).

\section{Gene expression in tissues}

To test the possible contribution of $\mathrm{Mc} 4 \mathrm{r}$ to the reproductive dysfunction, RT-PCR was used to examine Mc4r expression in several tissues including pituitary gland, ovary, liver, muscle and fat. Mc4r mRNA was expressed in pituitary gland and ovary, but not in liver, muscle and fat (Fig. 5A). As shown in Fig. 5B, the expression of insulin receptor mRNA in the muscle from MC4R KO mice was significantly higher than that in WT LM mice. There was no difference in insulin receptor mRNA in liver, ovary, fat and pituitary tissues between MC4R KO mice and WT LM mice.

\section{Discussion}

Obesity is a major health problem worldwide due to its increasing prevalence and association with many chronic and potentially lethal diseases. Obesity is a consequence of multiple factors including increased food intake, decreased exercise and certain genetic defects (Marti et al. 2008, Keller et al. 2015, Sáinza et al. 2015). The MC4R, primarily expressed in the brain with high
A

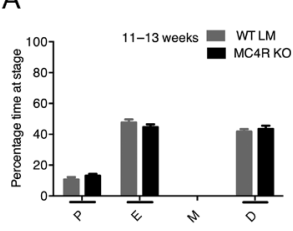

D
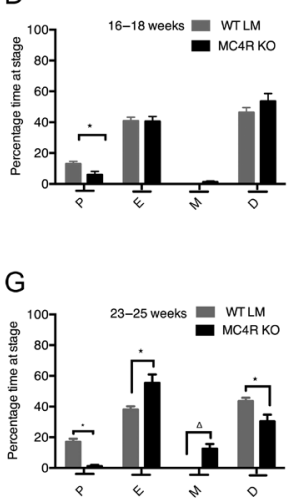

B

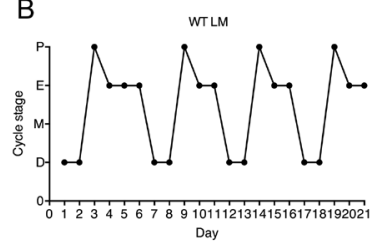

E
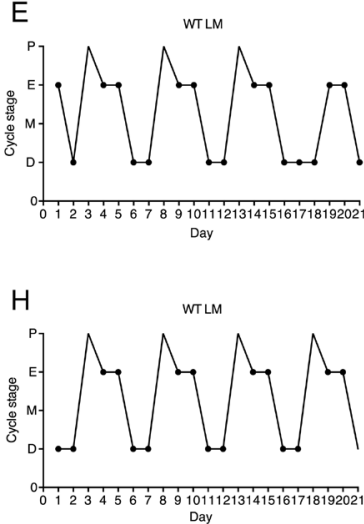

C

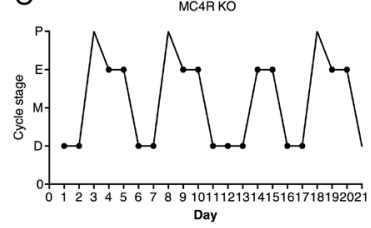

$\mathrm{F}$
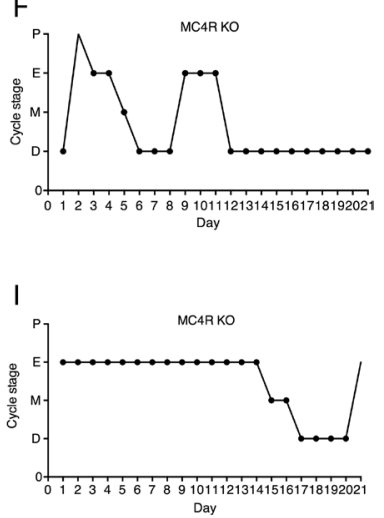

Figure 1 Altered irregular estrous cycles in MC4R KO mice. (A, B and C) Percentage of time spent in each stage ( $P$, proestrus; $E$, estrus; $M$, metestrus; $D$, diestrus) and representative data of vaginal cytology in WT LM and MC4R KO mice at $11-13$ weeks of age. (D, E, and F) Percentage of time spent in each stage and representative data of vaginal cytology in WT LM and MC4R KO mice at 16-18 weeks of age. $(\mathrm{G}, \mathrm{H}$, and $\mathrm{I})$ Percentage of time spent in each stage and representative data of vaginal cytology in WT LM and MC4R KO mice at 23-25 weeks of age. Data are mean \pm S.E.M. ${ }^{*} P<0.0001,{ }^{\Delta} P 0.01,{ }^{\star} P<0.05$. 

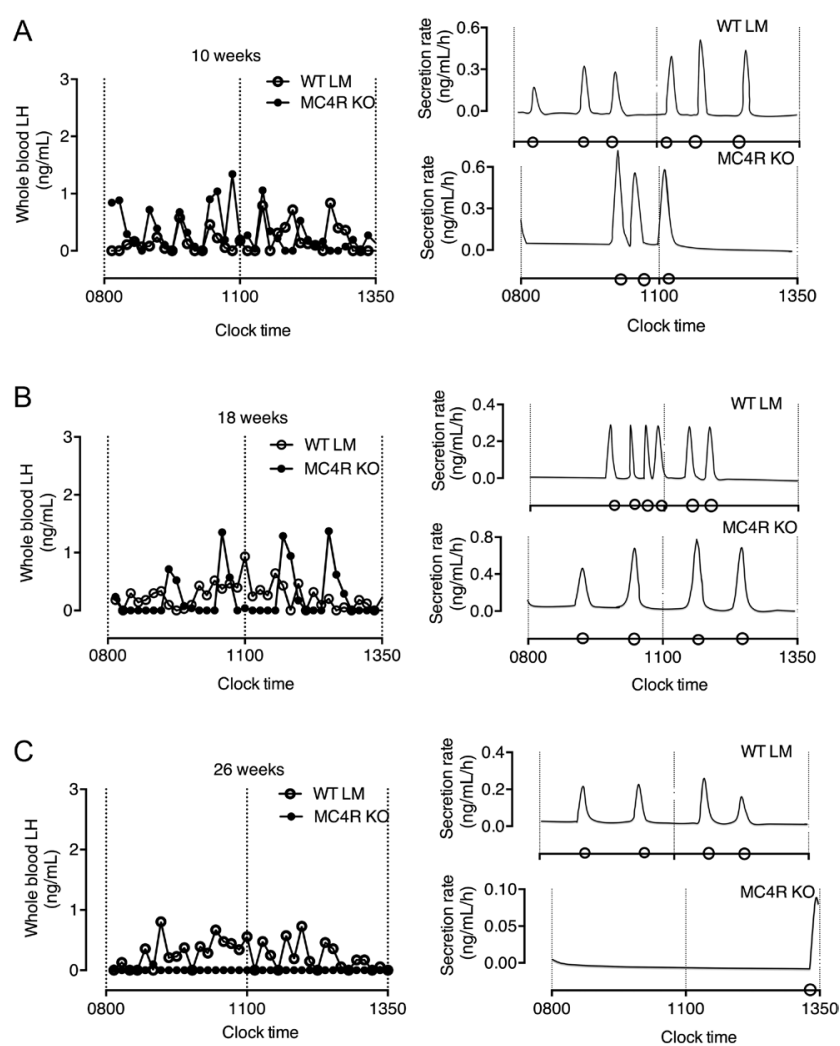

Figure 2 Representative profiles of pulsatile LH secretion and corresponding output figures in WT LM and MC4R KO mice. (A) At the age of 10 weeks. (B) At the age of 18 weeks. (C) At the age of 26 weeks.

levels in the hypothalamus, is thought to play a critical role in the regulation of energy balance (Mountjoy et al. 1994). In humans, locus variants in the MC $4 R$ cause severe obesity (Pan et al. 2013). In mice, lack of the MC4R results in hyperphagia, hyperinsulinemia and obesity (Huszar et al. 1997, Marie et al. 2000, Weide et al. 2003, Albarado et al. 2004, Xu et al. 2013). It is well known that obesity-associated hyperinsulinemia is a major risk factor for infertility (Allon et al. 2005, Evans et al. 2007, Moret et al. 2008). Male MC4R KO mice are characterized by erectile dysfunction and altered sexual behavior (Van der Ploeg et al. 2001).
Female MC4R KO mice demonstrate changes in ovarian morphology, reminiscent of polycystic ovary syndrome (PCOS) (Sandrock et al. 2009). Thus, detailed characterization of the hypothalamic-pituitary-LH axis in MC4R KO female mice may provide evidence to address the pathological neuroendocrine mechanism of obesity-related infertility. In addition, this research may help distinguish between the impact of hyperphagia on normal food-associated obesity and high-fat dietinduced obesity on reproductive ovary changes and infertility.

In the present study, we characterized the phenotypic profiles of MC4R KO female mice. Consistent with prior observations, MC4R KO female mice consumed approximately double the amount of food compared to age-matched WT LM mice. An approximate 15\% increase in body length was recorded for MC4R KO female mice at 16 weeks of age. These results were consistent with the documented effects of loss of MC4R in male mice (Tan et al. 2016). Alongside hyperphagia, fat pad weight (including subcutaneous and visceral) in MC4R KO mice was significantly elevated at 16 weeks of age. In addition, our results demonstrated that obesity is a well-established risk factor for type 2 diabetic mellitus. Previous studies suggest that both male and female MC4R $\mathrm{KO}$ mice develop insulin resistance, hyperinsulinemia and hyperglycemia (Huszar et al. 1997, Marie et al. 2000, Weide et al. 2003, Cui \& Lutter 2013, Xu et al. 2013, Arble et al. 2015). Results presented here also showed that the 12- to 20-week MC4R KO mice exhibited elevated fasting and postprandial blood glucose levels and insulin, alongside with decreased glucose disposition, insulin resistance and steatohepatitis. These phenotypic characteristics confirm the metabolic dysfunction of obese rodent models (Hill et al. 2010, Wu et al. 2012, 2014, Arble et al. 2015, Gao et al. 2015).

Polycystic ovary syndrome (PCOS), characterized by hyper-androgenemia, anovulation and polycystic ovaries, is one of the most common causes of infertility in women of reproductive age (Gambineri et al. 2002). Obesity is a common finding in women with PCOS and approximately $50 \%$ of women with PCOS are reported to be overweight or obese (Gambineri et al. 2002).

Table 4 Deconvolution and ApEn analysis parameters of pulsatile LH secretion from WT LM and MC4R KO female mice at stage of diestrus.

\begin{tabular}{|c|c|c|c|c|c|c|}
\hline & \multicolumn{2}{|c|}{10 weeks } & \multicolumn{2}{|c|}{18 weeks } & \multicolumn{2}{|c|}{26 weeks } \\
\hline & WT LM & MC4R KO & WT LM & MC4R KO & WT LM & MC4R KO \\
\hline Total LH secretion $(\mathrm{ng} / \mathrm{mL} / 6 \mathrm{~h})$ & $11.92 \pm 2.24$ & $8.47 \pm 3.20$ & $26.61 \pm 11.10$ & $26.06 \pm 8.95$ & $15.27 \pm 3.16$ & $0.64 \pm 0.13^{\Delta}$ \\
\hline Pulsatile $\mathrm{LH}$ secretion rate $(\mathrm{ng} / \mathrm{mL} / 6 \mathrm{~h})$ & $10.63 \pm 1.55$ & $7.91 \pm 3.39$ & $20.64 \pm 10.55$ & $25.66 \pm 8.97$ & $9.46 \pm 3.11$ & $0.28 \pm 0.13^{\star}$ \\
\hline Mass of LH secreted/burst (MPP) (ng/mL) & $2.48 \pm 0.37$ & $1.80 \pm 0.66$ & $2.55 \pm 0.76$ & $4.82 \pm 0.92$ & $1.71 \pm 0.50$ & $0.28 \pm 0.13^{\star}$ \\
\hline Basal LH secretion rate $(\mathrm{ng} / \mathrm{mL} / 6 \mathrm{~h})$ & $1.29 \pm 0.93$ & $0.56 \pm 0.20$ & $5.97 \pm 2.22$ & $0.39 \pm 0.03^{\star}$ & $5.81 \pm 1.99$ & $0.36 \pm 0.00^{\star}$ \\
\hline No. of pulses/6h & $4.50 \pm 0.87$ & $4.00 \pm 0.58$ & $7.00 \pm 1.35$ & $5.00 \pm 1.00$ & $5.67 \pm 0.88$ & $0.25 \pm 0.25^{\Delta}$ \\
\hline Half-life (min) & $2.58 \pm 0.92$ & $3.99 \pm 2.33$ & $4.99 \pm 1.49$ & $4.23 \pm 1.02$ & $5.53 \pm 1.79$ & $1.73 \pm 0.02$ \\
\hline ApEN, 1, 0.35 & $0.49 \pm 0.12$ & $0.45 \pm 0.04$ & $0.90 \pm 0.04$ & $0.57 \pm 0.03^{\#}$ & $0.92 \pm 0.14$ & $0.00 \pm 0.00^{\Delta}$ \\
\hline
\end{tabular}

Samples were collected at 10-min intervals between 08:00 and 14:00 h. Data are presented as mean \pm S.E.M.; $n=4$ per group. Statistical differences were evaluated by Mann-Whitney test.

${ }^{\sharp} P<0.001, \Delta P<0.01,{ }^{\star} P<0.05$.

ApEN, approximate entropy. 
A

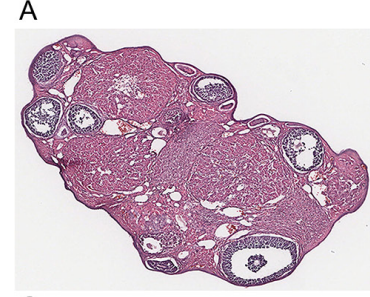

C

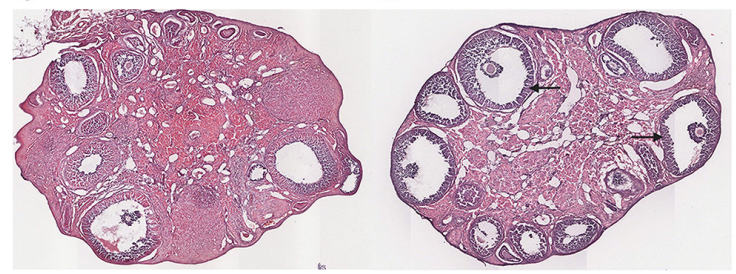

B

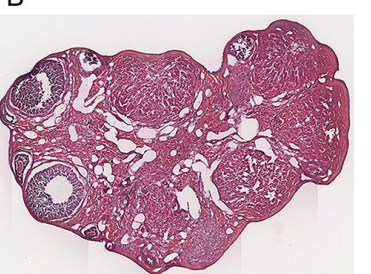

D
E
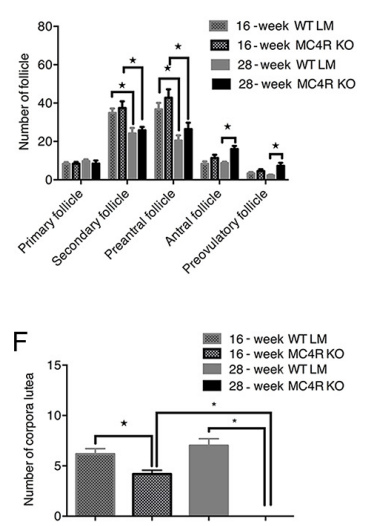

Figure $3 \mathrm{MC} 4 \mathrm{R}$ KO mice exhibit increased number of antral and pre-ovulatory and decreased number of corpora lutea. Representative images of H\&E-stained ovary frozen sections. (A) 16-week-old WT LM mice. (B) 28-week-old WT LM mice. (C) 16-weekold MC4R KO mice. (D) 28-week-old MC4R $\mathrm{KO}$ mice. Black arrows point antral and pre-ovulatory follicles. (E) The number of follicles at all stages in WT LM and MC4R KO mice. (F) Total corpora lutea counts from WT LM and MC4R KO mice. ( $n=6-8$ mice per group). Data are represented as mean \pm S.E.M. ${ }^{*} P<0.0001,{ }^{\star} P<0.05$.
Although the etiology of PCOS is uncertain, clinical studies demonstrate that women with PCOS exhibit increased $\mathrm{LH}$ levels, LH/FSH ratios and $\mathrm{LH}$ pulse frequency and amplitude (Ehrmann 2005, Roland \& Moenter 2014). Similar endocrine disorders have been observed in obesity-induced ovulatory dysfunction in many species, especially in models of high-fat diet (HFD)-induced obesity (Sanchez-Garrido \& TenaSempere 2013, Zhou et al. 2014) without detailed analysis of $\mathrm{GnRH}-\mathrm{LH}$ profiles. In the present study, we observed the estrous cycle and pulsatile LH secretion during three carefully selected periods (11-13 weeks, 16-18 weeks and 23-25 weeks) in Mc4r gene-knockout female mice. Our observation showed that reproductive ability declined progressively in obese MC4R KO female mice. At the age of 10-13 weeks, MC4R KO mice and WT LM mice displayed similar estrous cycle patterns and LH pulsatile profiles, demonstrating that MC4R KO mice had an approximate normal hypothalamus-pituitarygonadal axis at this early stage. MC4R KO mice had, however, a significantly more irregular estrous cycle in the 16- to 18-week age range and exhibited a decrease in basal LH secretion rate and irregularity. At the age of 23-25 weeks, MC4R KO mice remained in persistent estrus, showing a marked decrease in $\mathrm{LH}$ secretion. All of these results obtained in MC4R KO mice were
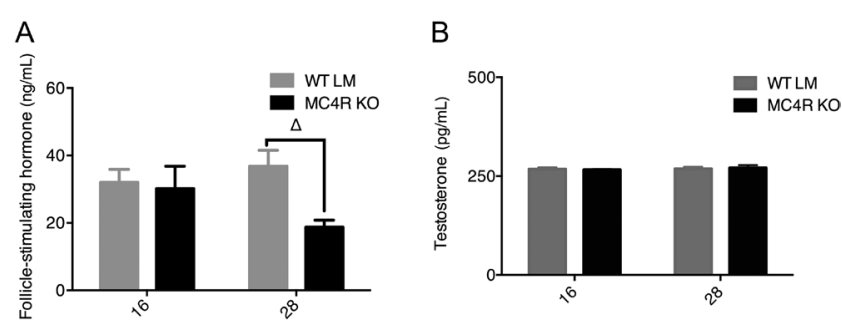

Figure $4 \mathrm{MC} 4 \mathrm{R}$ KO mice exhibit decreased circulating FSH level and normal circulating testosterone level. (A) Circulating FSH and (B) testosterone levels in WT LM and MC4R KO mice at 16 and 28 weeks of age ( $n=7-8$ mice per group). Data are mean \pm S.E.M. ${ }^{\Delta} P<0.01$. different to those in HFD-induced obesity mice, which exhibited persistent diestrus and elevated serum $\mathrm{LH}$ levels similar to PCOS women (Akamine et al. 2010, Sanchez-Garrido \& Tena-Sempere 2013, Wu et al. 2014, Zhou et al. 2014). The hyperinsulinemia has been implicated to increase LH release and potentiate gonadotropin-stimulated steroidogenesis in granulosa and thecal cells (Zhang \& Veldhuis 2004). However, the secretion of $\mathrm{LH}$ in obese MC4R KO female mice was decreased. Prior to this study, data showing growth hormone $(\mathrm{GH})$ release in MC4R KO male mice demonstrated the suppression of $\mathrm{GH}$ release alongside increased adiposity and the progressive worsening of hyperphagia-associated hyperinsulinemia (Tan et al. 2016). Then, by restricting calorie intake to prevent hyperphagia in MC4RKO male mice, it maintained an increase in adipose mass, attenuated hyperinsulinemia, recovered $\mathrm{GH}$ release and normalized linear growth rate. This evidence indicates that the suppression of $\mathrm{GH}$ release in MC4RKO mice occurs independent of increased adipose mass and is a consequence of hyperphagia-associated hyperinsulinemia. Therefore, we postulate that hyperphagia and hyperinsulinemia in MC4R KO mice might be involved in regulating $\mathrm{LH}$ secretion profiles in this report. The MC4R KO mice in
A

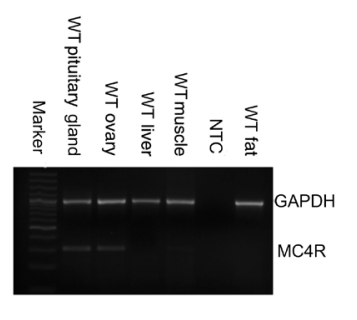

B

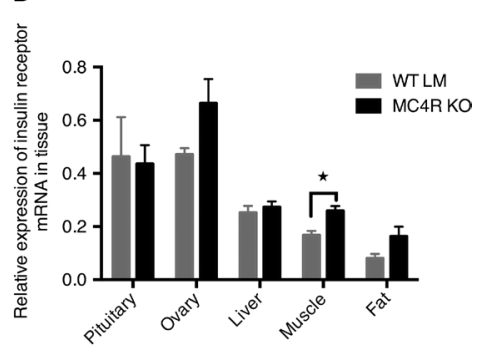

Figure 5 (A) Expression of MC4R in pituitary, ovary, liver, muscle and fat tissues. MC4R mRNA expressed within pituitary gland and ovary. NTC, negative control. (B) The expression of insulin receptor mRNA in pituitary, ovary, liver, muscle and fat tissue from MC4R KO mice $\left(n=4\right.$ mice per group). Data are mean \pm S.E.M. ${ }^{\star} P<0.05$. 
this report displayed no proestrus and fewer number of corpora lutea in ovary, implicating dysfunction of ovary and suggesting an increase in estradiol and inhibin levels in circulation.

To analyze the effects of MC4R on ovulation, we further determined the presence of follicles and corpora lutea in ovaries from 16-week and 28-week MC4R KO mice. Compared with WT LM mice, increased numbers of antral and preovulatory follicles were observed in ovaries from MC4R KO mice. In addition, the number of corpora lutea, an estimation of the ovulation rate, decreased significantly in MC4R KO mice at 16 weeks of age, and no detectable corpora lutea at 28 weeks of age. This finding was supported by the extension of estrus stage in 28-week MC4R KO mice. Furthermore, this result was consistent with the lack of LH surge and decrease in basal $\mathrm{LH}$ secretion in matured MC4R $\mathrm{KO}$ mice.

Although the mechanisms through which MC4R affects the pulsatile $\mathrm{LH}$ secretion and reproductive function remain inconclusive, obesity and hyperinsulinemia may be essential to cause anovulation as often observed in obese patients. In the present study, 8-week MC4R KO female mice presented normal blood sugar and insulin levels, despite an increased body weight. MC4R KO female mice presented approximate normal pulsatile LH secretion and regular estrous cycle. Along the increase in age, 12-week MC4R KO female mice still presented regular estrous cycle although both blood sugar and insulin levels started to increase, accompanied by the aggravated obesity. In MC4R KO mice over 16-week age, hyperinsulinemia occurred together with decreased $\mathrm{LH}$ release, irregular estrous cycle and alteration of ovarian morphology. It is strongly suggested that obesity and hyperinsulinemia (rather than missing MC4R) also contribute to regulating $\mathrm{LH}$ synthesis and release in MC4R KO mice.

Previous studies indicated that HFD-induced severe and rapid obese female mice exhibited high testosterone levels similar to obese women with PCOS. Androgen biosynthesis is mediated by cytochrome P450 17alpha hydroxylase (P450Cyp17), which is present in the thecainterstitial cells of the ovary. P450Cyp17 is encoded by the Cyp17 gene, which is regulated by insulin. Insulin has been documented to synergize with $\mathrm{LH}$ to stimulate testosterone synthesis in vitro (Bucholtz et al. 2000, Zhang \& Veldhuis 2004, Kim et al. 2005, Nestler et al. 2005, Hill et al. 2010, Wu et al. 2012, 2014). However, it is not clear whether insulin can stimulate androgen secretion independently of $\mathrm{LH}$. The present study demonstrates that MC4R KO obese female mice exhibit hyperinsulinemia and low LH levels, as well as normal testosterone levels. The cause of normal testosterone levels may be due to the low serum LH levels in obese MC4R KO female mice. Insulin alone may not be able to stimulate androgen synthesis in obese MC4R
$\mathrm{KO}$ female mice. Current clinic treatment of PCOS to reduce testosterone may also be achieved by reducing LH levels.

A pituitary-specific insulin receptor knockout lean mouse exhibited normal fertility rates, estrous cycles, $\mathrm{LH}$ and FSH levels and normal numbers of corpora lutea (Sanchez-Garrido \& Tena-Sempere 2013). HFD-induced obesity in this mouse model demonstrated an improved fertility rate, whereas deletion of insulin receptor substrate-2 (IRS-2) results in female mice infertility with decreased serum LH levels (Burks et al. 2000, Sanchez-Garrido \& Tena-Sempere 2013). In addition, specific knockout of the insulin receptor in GnRH neurons improves fertility and $\mathrm{LH}$ and $\mathrm{GnRH}$ secretion in HFD-induced obese female mice (DiVall et al. 2015). This suggests that insulin and its downstream signaling may play a role in modulating pulsatile $\mathrm{LH}$ release. In the current study, MC4R KO mice exhibited similar insulin receptor mRNA levels in the pituitary, ovary and liver to WT LM mice, but the insulin receptor and downstream signal proteins in these tissues have not been investigated. The observed changes of $\mathrm{LH}$ profiles including irregularities suggest the effect of hyperinsulinemia on both $\mathrm{GnRH}$ and $\mathrm{LH}$ cells. Thus, the role of the insulin receptor and its downstream signaling in mediating reproductive LH surge warrants further investigations into $\mathrm{GnRH}-\mathrm{LH}$ axis. Approximately $70 \%$ of $\mathrm{GnRH}$ neurons are activated by $\alpha-\mathrm{MSH}$ through a direct postsynaptic activation of MC4R (Roa \& Herbison 2012), and Mc4r mRNA was detected in the pituitary and ovaries in this report (Fig. 5). It is likely that MC4R may directly participate in the regulation of the hypothalamus-pituitary-ovary axis, in addition to indirect involvement via hyperphagia and obesity. Further study is warranted to either confirm or exclude the involvement.

Collectively, this study indicates that MC4R KO mice developed metabolic characteristics and reproductive dysfunction different from that seen in mice with HFDinduced obesity, with much lower levels of LH and testosterone. It demonstrates that disturbance of MC4R causes hyperinsulinemia, hyperphagia and subsequent reduced GnRH-LH secretion and dysfunction of ovary in mice.

\section{Declaration of interest}

The authors declare that there is no conflict of interest that could be perceived as prejudicing the impartiality of the research reported.

\section{Funding}

This work is supported by Australian NHMRC, University of Queensland and China Scholarship Council. 


\section{Acknowledgments}

The authors greatly appreciate the assistance and support from staff and animal technicians at the School of Chemistry and Molecular Biosciences and the assistance from Dr Frederik Steyn (UQCCR and SBMS, UQ), Dr Shaun Walters (Research Facilities Manager, SBMS, UQ) and Prof. Lingling Jiang (Hebei Medical University, China).

\section{References}

Akamine EH, Marcal AC, Camporez JoP, Hoshida MS, Caperuto LC, Bevilacqua E \& Carvalho CRO 2010 Obesity induced by high-fat diet promotes insulin resistance in the ovary. Journal of Endocrinology 206 65-74. (doi:10.1677/JOE-09-0461)

Albarado DC, Mcclaine J, Stephens JM, Mynatt RL, Ye J, Bannon AW, Richards WG \& Butler AA 2004 Impaired coordination of nutrient intake and substrate oxidation in melanocortin-4 receptor knockout mice. Endocrinology 145 243-252. (doi:10.1210/en.2003-0452)

Allon MA, Leach RE, Dunbar J \& Diamond MP 2005 Effects of chronic hyperandrogenism and_or administered central nervous system insulin on ovarian manifestation and gonadotropin and steroid secretion. Fertility and Sterility 83 1319-1326. (doi:10.1016/j.fertnstert.2004.12.028)

Arble DM, Holland J, Ottaway N, Sorrell J, Pressler JW, Morano R, Woods SC, Seeley RJ, Herman JP, Sandoval DA et al. 2015 The melanocortin-4 receptor integrates circadian light cues and metabolism. Endocrinology 156 1685-1691. (doi:10.1210/en.2014-1937)

Bowe JE, Franklin ZJ, Hauge-Evans AC, King AJ, Persaud SJ \& Jones PM 2014 Metabolic phenotyping guidelines: assessing glucose homeostasis in rodent models. Journal of Endocrinology 222 G13-G25. (doi:10.1530/ JOE-14-0182)

Brothers KJ, Wu S, DiVall SA, Messmer MR, Kahn CR, Miller RS, Radovick S, Wondisford FE \& Wolfe A 2010 Rescue of obesity-induced infertility in female mice due to a pituitary-specific knockout of the insulin receptor (IR). Cell Metabolism 12 295-305. (doi:10.1016/j.cmet.2010.06.010)

Bucholtz DC, Chiesa A, Pappano WN, Nagatani S, Tsukamura H, Maeda K-I \& Foster DL 2000 Regulation of pulsatile luteinizing hormone secretion by insulin in the diabetic male lamb. Biology of Reproduction 62 1248-1255. (doi:10.1095/biolreprod62.5.1248)

Burks DJ, Mora JFd, Schubert M, Withers DJ, Myers MG, Towery HH, Altamuro SL, Flint CL \& White MF 2000 IRS-2 pathways integrate female reproduction and energy homeostasis. Nature 407 377-382. (doi:10.1038/35030105)

Byers SL, Wiles MV, Dunn SL \& Taft RA 2012 Mouse estrous cycle identification tool and image. PLOS ONE 7 e35538. (doi:10.1371/ journal.pone.0035538)

Clarke IJ \& Cummins JT 1985 GnRH pulse frequency determines LH pulse amplitude by altering the amount of releasable LH in the pituitary glands of ewes. Reproduction 73 425-431. (doi:10.1530/jrf.0.0730425)

Crujeiras AB \& Casanueva FF 2015 Obesity and the reproductive system disorders. Human Reproduction Update 21 249-261. (doi:10.1093/ humupd/dmu060)

Cui H \& Lutter M 2013 The expression of MC4Rs in D1R neurons regulates food intake and locomotor sensitization to cocaine. Genes, Brain and Behavior 12 658-665. (doi:10.1111/gbb.12057)

DiVall SA, Herrera D, Sklar B, Wu S, Wondisford F, Radovick S \& Wolfe A 2015 Insulin receptor signaling in the GnRH neuron plays a role in the abnormal GnRH pulsatility of obese female mice. PLOS ONE 10 e0119995. (doi:10.1371/journal.pone.0119995)

Ehrmann DA 2005 Polycystic ovary syndrome. New England Journal of Medicine 352 1223-1236. (doi:10.1056/NEJMra041536)

Lerchbaum E, Schwetz V, Rabe T, Giuliani A \& Pietsch BO 2014 Hyperandrogenemia in polycystic ovary syndrome-exploration of the role of free testosterone and androstenedione in metabolic phenotype. PLOS ONE 9 e108263. (doi:10.1371/journal.pone.0108263)

Evans WS, Taylor AE, Boyd DG, Johnson ML, Matt DW, Jimenez Y \& Nestler JE 2007 Lack of effect of short-term diazoxide administration on luteinizing hormone secretion in women with polycystic ovary syndrome. Fertility and Sterility 88 118-124. (doi:10.1016/j.fertnstert.2006.11.109)
Foster DL, Jackson LM \& Padmanabhan V 2006 Programming of GnRH feedback controls timing puberty and adult reproductive activity. Molecular and Cellular Endocrinology 254-255 109-119. (doi:10.1016/j. mce.2006.04.004)

Gambineri A, Pelusi C, Vicennati V, Pagotto U \& Pasquali R 2002 Obesity and the polycystic ovary syndrome. International Journal of Obesity $\mathbf{2 6}$ 883-896. (doi:10.1038/sj.ijo.0801994)

Gao Q, Jia Y, Yang G, Zhang X, Boddu PC, Petersen B, Narsingam S, Zhu Y-J, Thimmapaya B, Kanwar YS et al. 2015 PPARa-deficient ob/ob obese mice become more obese and manifest severe hepatic steatosis due to decreased fatty acid oxidation. American Journal of Pathology 185 1396-1408. (doi:10.1016/j.ajpath.2015.01.018)

Hill JW, Elias CF, Fukuda M, Williams KW, Berglund ED, Holland WL, Cho Y-R, Chuang J-C, Xu Y, Choi M et al. 2010 Direct insulin and leptin action on pro opiomelan cortin neurons is required for normal glucose homeostas and fertility. Cell Metabolism 11 286-297. (doi:10.1016/j. cmet.2010.03.002)

Huszar D, Lynch CA, Fairchild-Huntress V, Dunmore JH, Fang Q, Berkemeier LR, Gu W, Kesterson RA, Boston BA, Cone RD et al. 1997 Targeted disruption of the melanocortin-4 receptor results in obesity in mice. Cell 88 131-141. (doi:10.1016/S0092-8674(00)81865-6)

Keller K, López SR \& Moreno MMC 2015 Association between meal intake behaviour and abdominal obesity in Spanish adults. Appetite 92 1-6. (doi:10.1016/j.appet.2015.04.077)

Kim HH, DiVall SA, Deneau RM \& Wolfe A 2005 Insulin regulation of GnRH gene expression through MAP kinase signaling pathways. Molecular and Cellular Endocrinology 242 42-49. (doi:10.1016/j.mce.2005.07.002)

Leisegang K, Bouic PJ, Menkveld R \& Henkel RR 2014 Obesity is associated with increased seminal insulin and leptin alongside reduced fertility parameters in a controlled male cohort. Reproductive Biology and Endocrinology 12 1-12. (doi:10.1186/1477-7827-12-1)

Levi-Setti PE, Cavagna M, Baggiani A, Zannoni E, Colombo GV \& Liprandi V $2004 \mathrm{FSH}$ and LH together in ovarian stimulation. European Journal of Obstetrics and Gynecology and Reproductive Biology 115 (Supplement 1) S34-S39. (doi:10.1016/j.ejogrb.2004.01.013)

Marie LS, Miura GI, Marsh DJ, Yagaloff K \& Palmiter RD 2000 A metabolic defect promotes obesity in mice lacking melanocortin-4 receptors. PANS 97 12339-12344. (doi:10.1073/pnas.220409497)

Marti A, Martinez-González MA \& Martinez JA 2008 Interaction between genes and lifestyle factors on obesity. Proceedings of the Nutrition Society 67 1-8. (doi:10.1017/S002966510800596X)

Mehlem A, Hagberg CE, Muhl L, Eriksson U \& Falkevall A 2013 Imaging of neutral lipids by oil red $\mathrm{O}$ for analyzing the metabolic status in health and disease. Nature Protocols 8 1149-1154. (doi:10.1038/nprot.2013.055)

Moret M, Stettler R, Rodieux F, Gaillard R, Waeber G, Wirthner D, Giusti V, Tappy L \& Pralong F 2008 Insulin modulation of luteinizing hormone secretion in normal female volunteers and lean polycystic ovary syndrome patients. Neuroendocrinology 89 131-139. (doi:10.1159/000160911)

Morton GJ, Cummings DE, Baskin DG, Barsh GS \& Schwartz MW 2006 Central nervous system control of food intake. Nature 443 289-295. (doi:10.1038/nature05026)

Mountjoy KG, Mortrud MT, Low MJ, Simerly RB \& Cone RD 1994 Localization of the melanocortin-4 receptor (MC4-R) in neuroendocrine and autonomic control circuits in the brain. Molecular Endocrinology 8 1298-1308. (doi:10.1210/me.8.10.1298)

Myers M, Britt KL, Wreford NG, Ebling FJ \& Kerr JB 2004 Methods for quantifying follicular numbers within the mouse ovary. Reproduction 127 569-580. (doi:10.1530/rep.1.00095)

Nestler JE, Jakubowicz DJ, Vargas AFD, Brik C, Quintero N \& Medina F 2005 Insulin stimulates testosterone biosynthesis by human thecal cells from women with polycystic ovary syndrome by activating its own receptor and using inositolglycan mediators as the signal transduction system. Journal of Clinical Endocrinology and Metabolism 83 2001-2005. (doi:10.1210/jc.83.6.2001)

Palermo R 2007 Differential actions of FSH and LH during folliculogenesis. Reproduction BioMedicine 15 326-337. (doi:10.1016/S14726483(10)60347-1)

Pan Q, Delahanty LM, Jablonski KA, Knowler WC, Kahn SE, Florez JC \& Franks PW 2013 Variation at the melanocortin 4 receptor gene and response to weight-loss interventions in the Diabetes Prevention Program. Obesity 21 E520-E526. (doi:10.1002/oby.20459) 
Roa J \& Herbison AE 2012 Direct regulation of GnRH neuron excitability by arcuate nucleus POMC and NPY neuron neuropeptides in female mice. Endocrinology 153 5587-5599. (doi:10.1210/en.2012-1470)

Roland AV \& Moenter SM 2014 Reproductive neuroendocrine dysfunction in polycystic ovary syndrome-insight from animal models. Frontiers in Neuroendocrinology 35 494-511. (doi:10.1016/j.yfrne.2014.04.002)

Sáinza N, Barrenetxea J, Moreno-Aliaga MJ \& Martínez JA 2015 Leptin resistance and diet-induced obesity - central and peripheral actions of leptin. Metabolism Clinical and Experimental 64 35-46. (doi:10.1016/j. metabol.2014.10.015)

Sanchez-Garrido MA \& Tena-Sempere M 2013 Metabolic control of puberty-roles of leptin and kisspeptins. Hormones and Behavior 62 187-194. (doi:10.1016/j.yhbeh.2013.01.014)

Sandrock M, Schulz A, Merkwitz C, Schöneberg T, Spanel-Borowski K \& Ricken A 2009 Reduction in corpora lutea number in obese melanocortin-4-receptor-deficient mice. Reproductive Biology and Endocrinology 7 1-9. (doi:10.1186/1477-7827-7-1)

Shaw AM, Irani BG, Moore MC, Haskell-Luevano C \& Millard WJ 2005 Ghrelin-induced food intake and growth hormone secretion are altered in melanocortin 3 and 4 receptor knockout mice. Peptides 26 1720-1727. (doi:10.1016/j.peptides.2004.12.026)

Sliwowska JH, Fergani C, Gawałek M, Skowronska B, Fichna P \& Lehman MN 2014 Insulin: its role in the central control of reproduction. Physiology and Behavior 133 197-206. (doi:10.1016/j.physbeh.2014.05.021)

Steyn FJ, Wan Y, Clarkson J, Veldhuis JD, Herbison AE \& Chen C 2013 Development of a methodology for and assessment of pulsatile luteinizing hormone secretion in juvenile and adult male mice. Endocrinology 154 4939-4945. (doi:10.1210/en.2013-1502)

Tan HY, Steyn FJ, Huang L, Cowley M, Veldhuis JD \& Chen C 2016 Hyperphagia in male melanocortin 4 receptor deficient mice promotes growth independent of growth hormone. Journal of Physiology In press. (doi:10.1113/jp272770)

Tung YCL, Piper SJ, Yeung D, O'Rahilly S \& Coll AP 2006 A Comparative study of the central effects of specific proopiomelancortin (POMC)derived melanocortin peptides on food intake and body weight in pomc null mice. Endocrinology 147 5940-5947. (doi:10.1210/en.2006-0866)
Van der Ploeg LH, Martin WJ, Howard AD, Nargund RP, Austin CP, Guan X, Drisko J, Cashen D, Sebhat I, Patchett AA et al. 2001 A role for the melanocortin 4 receptor in sexual function. PNAS 99 11381-11386. (doi:10.1073/pnas.172378699)

Weide K, Christ N, Moar KM, Arens J, Hinney A, Mercer JG, Eiden S \& Schmidt I 2003 Hyperphagia, not hypometabolism, causes early onset obesity in melanocortin-4 receptor knockout mice. Physiological Genomics 13 47-56. (doi:10.1152/physiolgenomics.00129.2002)

Wu S, Divall S, Wondisford F \& Wolfe A 2012 Reproductive tissues maintain insulin sensitivity in diet-induced obesity. Diabetes $\mathbf{6 1}$ 114-123. (doi:10.2337/db11-0956)

Wu S, Divall S, Nwaopara A, Radovick S, Wondisford F, Ko C \& Wolfe A 2014 Obesity-induced infertility and hyperandrogenism are corrected by deletion of the insulin receptor in the ovarian theca cell. Diabetes $\mathbf{6 3}$ 1270-1282. (doi:10.2337/db13-1514)

Xu Y, Wu Z, Sun H, Zhu Y, Kim ER, Lowell BB, Arenkiel BR, Xu Y \& Tong Q 2013 Glutamate mediates the function of melanocortin receptor 4 on Sim1 neurons in body weight regulation. Cell Metabolism 18 860-870. (doi:10.1016/j.cmet.2013.11.003)

Zhang G \& Veldhuis JD 2004 Insulin drives transcriptional activity of the CYP17 gene in primary cultures of swine theca cells. Biology of Reproduction 70 1600-1605. (doi:10.1095/biolreprod.103.019646)

Zhou Q, Chen H, Yang S, Li Y, Wang B, Chen Y \& Wu X 2014 High-fat diet decreases the expression of Kiss1 mRNA and kisspeptin in the ovary, and increases ovulatory dysfunction in postpubertal female rats. Reproductive Biology and Endocrinology 12 1-11. (doi:10.1186/14777827-12-1)

Received 25 June 2016

First decision 23 July 2016

Revised manuscript received 28 November 2016

Accepted 5 December 2016 